\title{
The Global Burden of Musculoskeletal Injuries
}

\section{Challenges and Solutions}

\author{
Charles Mock MD, PhD, Meena Nathan Cherian MD
}

Published online: 5 August 2008

(C) The Association of Bone and Joint Surgeons 2008

\begin{abstract}
Musculoskeletal injuries are a major public health problem globally, contributing a large burden of disability and suffering. This burden could be considerably lowered by implementation of affordable and sustainable strategies to strengthen orthopaedic trauma care, especially in low- and middle-income countries. This article summarizes the global burden of musculoskeletal injuries and provides several examples of successful programs that have improved care of injuries in health facilities in low- and middle-income countries. Finally, it discusses WHO efforts to build on the country experiences and to make progress in lowering the burden of musculoskeletal injuries globally.
\end{abstract}

The author certifies that he has no commercial associations (e.g., consultancies, stock ownership, equity interest, patent/licensing arrangements, etc.) that might pose a conflict of interest in connection with the submitted article.

Presented in part at the ABJS/Carl T. Brighton Workshop on Musculoskeletal Trauma in Low and Middle Income Countries, Ahmedabad, India, December 11-14, 2007.

Disclaimer: The authors are staff members of the World Health Organization. The authors alone are responsible for the views expressed in this publication and they do not necessarily represent the decisions or policies of the World Health Organization.

\section{Mock $(\bowtie)$}

Department of Violence and Injury Prevention and Disability, WHO, 20 Avenue Appia, 1211 Geneva 27, Switzerland e-mail: mockc@who.int

M. N. Cherian

Department of Essential Health Technologies, WHO, Geneva, Switzerland

\section{Introduction}

Injury has become a major cause of death and disability globally. This is true in countries at all economic levels. There is often a misperception that injuries are primarily a health problem of high-income countries. To the contrary, injury mortality rates are significantly higher in most lowand middle-income countries (LMICs). Mortality rates from injury are higher in LMICs compared with high-income countries (HICs) (Table 1). This is in part due to rising rates of injuries from increased use of motorized transport and also due to less developed trauma care systems [12].

The rates of injury have been coming down in HICs due to a combination of injury prevention and improved trauma care. At the same time, rates of injury-related death and disability have been steadily rising in most LMICs. As the world's population primarily lives in LMICs, these trends have led to increasing rates of injury globally. If current trends continue, most injury-related causes of death will rise in their ranking of global disease burden.

For every person who dies from injury, many more are injured, with temporary or permanent disability. We do not have as comprehensive global data for these non-fatal injuries as we do for death. However, the data that we do have are fairly unanimous and uncontroversial in showing a huge burden of disability from musculoskeletal injuries. Some of these data come from individual country studies, such as a population-based survey that showed that $0.83 \%$ of Ghanaians had an injury-related disability. The vast majority (78\%) of such disabilities were due to extremity injuries. Such disabilities should be readily amenable to low-cost improvements in orthopaedic care and rehabilitation, in contrast to the more difficult to treat neurological injuries (head and spinal) that are relatively more frequent causes of disability in high-income countries [9]. 
Table 1. Deaths per 100,000 from injury by economic region of the world [22]

\begin{tabular}{lcc}
\hline & HIC & LMIC \\
\hline Road traffic & 13 & 20 \\
Poisoning & 2 & 6 \\
Falls & 8 & 6 \\
Fires & 1 & 6 \\
Drowning & 2 & 7 \\
Other unintentional & 9 & 16 \\
Suicide & 14 & 14 \\
Violence & 2 & 10 \\
War & 0.06 & 3 \\
Total & 50 & 88 \\
\hline
\end{tabular}

Source: WHO Global Burden of Disease Database, 2002 (version 5) [22].

HIC $=$ high-income countries $;$ LMIC $=$ low- and middle-income countries.

We do have some global data on non-fatal injuries. For example, the Global Burden of Disease (GBD) study evaluated rates of admission for various non-fatal injuries. It can be seen (Table 2) that the majority of these are musculoskeletal injuries, including open wounds, fractures, and other types of injuries. As with fatal injuries, such nonfatal musculoskeletal injuries mostly affect those living in LMICs. The GBD estimated that combined rates of extremity injury from falls and road traffic crashes ranged from 1000 to $2600 / 100,000$ per year in LMICs compared with 500/100,000 per year in HICs (e.g. two to five times higher in LMICs) [21].

Although we do have some global data on rates on nonfatal injuries, it is not enough. There are ongoing efforts to develop better global data on these non-fatal injuries, including musculoskeletal injuries, through the GBD study.

Despite this large burden of death and disability from injury, there has been a grossly inadequate response in terms of policy and funding. The amount of funding and effort devoted to injury prevention, trauma and basic surgical care are miniscule in comparison to other significant global health problems, such as HIV/AIDS and other infectious diseases. In part this lack of attention is due to the misperceptions that injuries arise from "accidents" that are due to carelessness and bad luck and thus consequently little can be done to prevent them. However, a great deal can be done to successfully lower the rates of injury, by addressing the spectrum of injury control: (1) improving the base of knowledge through research and surveillance; (2) improving safety and implementing scientifically-proven injury prevention strategies; (3) strengthening prehospital trauma care; and (4) strengthening hospitalbased trauma care, including emergency surgical care and long-term rehabilitation. A necessary component of item 4
Table 2. The 20 leading non-fatal injuries sustained* as a result of road traffic collisions, world, 2002

\begin{tabular}{|c|c|c|}
\hline Type of injury sustained & $\begin{array}{l}\text { Rate per } \\
100,000 \\
\text { population }\end{array}$ & $\begin{array}{l}\text { Proportion } \\
\text { of all traffic } \\
\text { injuries }\end{array}$ \\
\hline Intracranial injury $^{\dagger}$ (short-term ${ }^{*}$ ) & 85.3 & 24.6 \\
\hline Open wound & 35.6 & 10.3 \\
\hline Fractured patella, tibia or fibula & 26.9 & 7.8 \\
\hline Fractured femur (short-term ${ }^{*}$ ) & 26.1 & 7.5 \\
\hline Internal injuries & 21.9 & 6.3 \\
\hline Fractured ulna or radius & 19.2 & 5.5 \\
\hline Fractured clavicle, scapula or humerus & 16.7 & 4.8 \\
\hline Fractured facial bones & 11.4 & 3.3 \\
\hline Fractured rib or sternum & 11.1 & 3.2 \\
\hline Fractured ankle & 10.8 & 3.1 \\
\hline Fractured vertebral column & 9.4 & 2.7 \\
\hline Fractured pelvis & 8.8 & 2.6 \\
\hline Sprains & 8.3 & 2.4 \\
\hline Fractured skull (short-term ${ }^{*}$ ) & 7.9 & 2.3 \\
\hline Fractured foot bones & 7.2 & 2.1 \\
\hline Fractured hand bones & 6.8 & 2.0 \\
\hline Spinal cord injury (long-term ${ }^{\S}$ ) & 4.9 & 1.4 \\
\hline Fractured femur (long-term ${ }^{\S}$ ) & 4.3 & 1.3 \\
\hline Intracranial injury $^{\dagger}\left(\right.$ long-term $\left.^{\S}\right)$ & 4.3 & 1.2 \\
\hline Other dislocation & 3.4 & 1.0 \\
\hline
\end{tabular}

* Requiring admission to a health facility; ${ }^{\dagger}$ Traumatic brain injury; ${ }^{ }$Short term = lasts only a matter of weeks; ${ }^{\S}$ Long term = lasts until death, with some complications resulting in reduced life expectancy. Source: WHO Burden of Disease Study, 2002, version 1 data [22].

Reproduced with permission from World Report on Road Traffic Injury Prevention [15].

is building capacities in emergency and essential surgical and anesthesia services at existing first referral level health facilities.

As this review is focused on the potential gains that could be made by strengthening emergency and essential trauma and surgical care received by the injured, it is instructive to look at existing discrepancies in outcome by region of the world. One study showed that mortality rates for serious injuries (Injury Severity Score $\geq 9$ ) varied with economic status, going from $35 \%$ in high-income Seattle, USA, to $55 \%$ in middle-income Monterrey, Mexico, to $63 \%$ in low-income Kumasi, Ghana. Thus, mortality rates for the seriously injured are nearly twice as high in lowincome settings as in HICs [14]. Each year over 5,000,000 people die from injuries, with $95 \%$ of these deaths in LMICs [7]. If we could eliminate the disparities in injury outcome among those who are seriously injured and bring down injury case fatality rates in LMICs from their current high rates to the rates in HICs, we could potentially save $2,000,000$ lives per year. If injury mortality rates could 
even be brought down by a more conservative $8 \%, 400,000$ lives could be saved each year [17].

\section{Case Studies of Successful Programs from Individual Institutions}

Despite the fact that resources in most LMICs are very limited, many individuals and institutions have reported innovative solutions to improve the outcomes of trauma care, oftentimes working in very difficult circumstances. There are many such examples to report. This section will point out just a few illustrative examples.

In Mexico, increased number of ambulance stations (to allow more rapid dispatch) decreased the response times to reach injured victims. Improved training (in more regular use of the Prehospital Trauma Life Support Course) led to improved process of care in the field. The net result was a decrease in mortality from $8.2 \%$ to $4.7 \%$, among transported trauma patients. These improvements resulted in a $16 \%$ increase in the ambulance service budget. However, this was sustainable within the local economy and these changes have been institutionalized and maintained by the local government [3].

In Trinidad, regular use of continuing medical education for trauma care (in the Advanced Trauma Life Support Course) resulted in significant improvements in the use of appropriate treatments for severely injured patients and a decrease in the mortality of severely injured patients at the main hospital in Trinidad, from $67 \%$ to $34 \%$ [1].

In Thailand, the main trauma hospital in Khon Kaen instituted a trauma audit committee to better oversee trauma care. This committee identified a high rate of preventable (e.g. medically preventable) deaths. It identified several correctable problems, such as inadequate resuscitation for shock, delayed surgery for head injuries, and problems with record keeping and communications. Low cost, corrective action was instituted to target these problems, including improved communication within the hospital by use of radios, better supervision of junior doctors through increased senior staffing in the ED (Emergency Department) at peak times, and improved reporting and monitoring of trauma cases at hospital meetings (e.g. better use of techniques of quality improvement). These improvements resulted in a decrease in mortality among all admitted trauma patients from $6.1 \%$ to $4.4 \%$ [5].

In Malawi, one hospital instituted a protocol for open fractures that emphasized primary external fixation, scheduled sequential débridement, coverage of exposed bone through local muscle flaps, controlled secondary healing, and early mobilization, all low-cost techniques that could be practiced well in the local circumstances and within the economic resources available. They reported recovery of normal function in $80 \%$ of patients, functional results similar to those from HICs [4].

These are obviously just a few brief examples. Many of the readers of CORR have similar success stories to report on from their own institutions. The question now is how to build on such individual institution experiences and make progress globally.

\section{Global Efforts to Improve Trauma Care}

The WHO has several mutually complimentary efforts to strengthen care of the injured globally, especially in LMICs. Care of the injured is built on a firm foundation of adequate surgical and anesthetic capabilities. Hence, the first one of these programs involves efforts to strengthen such capabilities, especially in small, rural hospitals, where resources are most constrained. This program has been notable in the development of training modules that are widely used in these resource constrained health facilities. The second of the WHO efforts emphasizes the development of policies to promote stronger trauma care systems, including both prehospital and facility based care. Thirdly, a recent resolution by the World Health Assembly has given added political endorsement to efforts to strengthen trauma care globally.

\section{Global Initiative for Emergency and Essential Surgical} Care

Musculoskeletal injuries needing urgent care are often amongst the commonest conditions at the first referral health facilities (health centers, district, rural or community hospitals). Often these facilities lack specialists such as orthopaedic and trauma surgeons, general surgeons, anesthesiologists, and emergency physicians. These conditions require timely emergency, and essential surgical and anesthesia interventions to reduce death and disability.

At these primary healthcare facilities the urgent care is usually provided by nonspecialist doctors, nurses, clinical officers/technicians, and paramedics. Often these caregivers work in very difficult, isolated circumstances, with limited equipment and supplies, with limited capability for urgent referral to more specialized centers, and with limited opportunity for continuing medical education. In order to help strengthen surgical care at such locations, WHO has responded by establishing the Clinical Procedures Unit in the Department of Essential Health Technologies. This unit was created to address the deficiencies in the provision of emergency and essential surgical care, including care of musculoskeletal injuries, as well as other surgically 
treatable conditions such as infections, pregnancy-related complications, acute abdominal conditions, and congenital anomalies.

WHO developed an Integrated Management for Emergency and Essential Surgical Care toolkit (IMEESC) [23] toolkit based on the WHO reference manual Surgical Care at the District Hospital [24]. The Emergency and Essential Surgical Care (EESC) Project employs an integrated comprehensive training package, the IMEESC toolkit, aimed at building capacities for health care providers in resource constrained settings, through "training of trainers" workshops held in collaboration with the Ministry of Health, supported by both local and international partners (Fig. 1).

Programs have been initiated in 24 countries: Mongolia, Vietnam, Philippines; Bangladesh, DPR Korea, India, Maldives, Nepal; Kyrgyzstan, Tajikistan; Afghanistan, Oman; Pakistan; Guyana; Ethiopia, Cote d'Ivoire, Gambia, Ghana, Kenya, Malawi, Mozambique, Tanzania, Uganda, Zambia; workshop reports are available at www.who.int/surgery.

The workshops utilize various methods for information transfer including lectures, role playing, "hands on" skills,

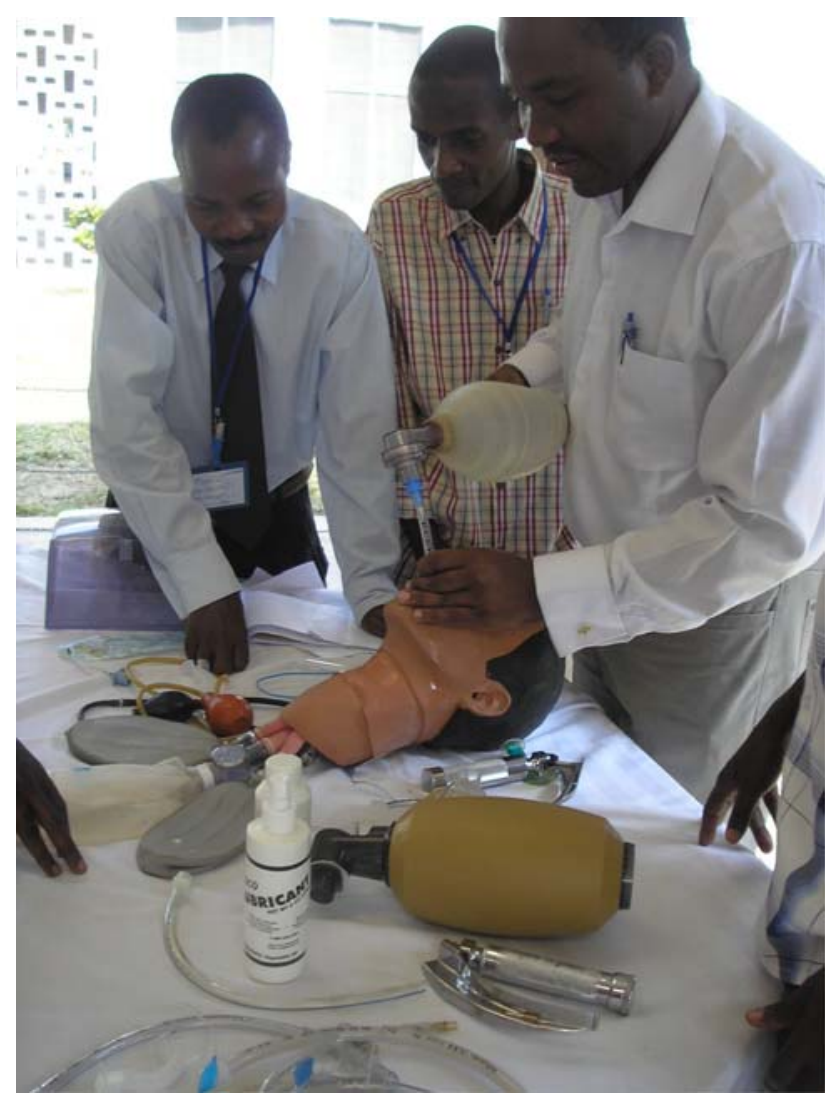

Fig. 1 The Emergency and Essential Surgical Care training workshop being held as joint undertaking of Ministry of Health and WHO in Tanzania is shown. Such collaborative training workshops have been held in 24 countries. local adaptations of training materials and e-learning sessions. Teaching materials include the WHO IMEESC toolkit, and the WHO reference manual Surgical Care at the District Hospital. Orthopaedic components of this toolkit and program include teaching power point slides, guidelines in disaster management, emergency and trauma care, splinting and casting techniques, closed treatment of fractures, management of open fractures and soft tissue wounds, and techniques for traction. In addition for a comprehensive package applicable to a first level referral health facility, some components are relevant to musculoskeletal injuries such as hand washing, antibiotic and tetanus prophylaxis, medical records, patient consent, sterilization of equipment, wound management, protocols on safe anesthesia and surgical procedures, prevention of HIV, postoperative care, and pain relief.

The WHO IMEESC toolkit includes training videos on management of wounds and fractures in adults and children. It provides guidance to decision makers on policies, needs assessment, minimum standards to improve essential surgical and anesthesia care, anesthesia infrastructure and supplies at various levels of care, training curriculum, and quality assurance through monitoring and evaluation. It also includes an inventory tool for emergency essential equipment for resuscitation (Table 3) which is a basic list and which can be supplemented with specific lists for trauma, obstetrics, and other surgical procedures.

In December of 2005, a Global Initiative for Emergency and Essential Surgical Care (GIEESC) was launched with the goal of fostering collaboration amongst stakeholders to promote the delivery of safe and appropriate emergency, surgical and anesthesia services at resource limited health care facilities. Key components of the GIEESC include strengthening capacities through training and education, supporting policy and implementation of EESC, advocacy, research, and the development and dissemination of appropriate technologies for primary health facilities in resource challenged environments. People interested in GIEESC may find more information on the project's website at: http://www.who.int/surgery/globalinitiative/en/.

\section{Strengthening Trauma Care Systems}

Several years ago, WHO's Department of Violence and Injury Prevention and Disability Department came out with two sets of recommendations, primarily oriented at the policy and Ministry of Health planning level, on ways to strengthen care of the injured, in both prehospital and hospital based settings. Prehospital Trauma Care Systems [18] gives recommendations on ways to institute formal Emergency Medical Services (EMS) e.g. usually encompassing ambulance systems. It also discusses what to do in 
Table 3. Emergency equipment and supplies for resuscitation (www.who.int/surgery/publications/imeesc/en/index.html)

\begin{tabular}{|c|c|c|c|c|c|}
\hline Capital outlays & Quantity & Date checked & Renewable items & Quantity & Date checked \\
\hline Resuscitator bag valve \& mask (adult) & & & Suction catheter sizes 16 FG & & \\
\hline Resuscitator bag valve \& mask (paediatric) & & & Tongue depressor wooden disposable & & \\
\hline Oxygen source: cylinder/concentrator & & & Nasogastric tubes 10 to $16 \mathrm{FG}$ & & \\
\hline Mask \& tubing to connect to oxygen supply & & & Light source (lamp \& flash light) & & \\
\hline Stethoscope & & & Intravenous fluid infusion set & & \\
\hline Batteries for flash light & & & IV cannula sizes $18,22,24$ & & \\
\hline Suction pump (manual or electric) & & & Scalp vein infusion set & & \\
\hline Blood pressure measuring equipment & & & Syringes $2 \mathrm{ml}$ & & \\
\hline Thermometer & & & Syringes $10 \mathrm{ml}$ & & \\
\hline Scalpel handle with blade & & & Disposable needles \# 25, 21,19 & & \\
\hline Retractor & & & Sharps disposal container & & \\
\hline Scissors straight $12 \mathrm{~cm}$ & & & Tourniquet & & \\
\hline Scissors blunt $14 \mathrm{~cm}$ & & & Sterile gauze dressing & & \\
\hline Oropharyngeal airway (adult size) & & & Bandages sterile & & \\
\hline Oropharyngeal airway (paediatric) & & & Adhesive Tape & & \\
\hline Forcep Kocher no teeth & & & Needles, cutting \& round bodied & & \\
\hline Forceps, artery & & & Suture synthetic absorbable & & \\
\hline Kidney dish stainless steel & & & Splints for arm, leg & & \\
\hline Capped bottle, alcohol based solutions & & & Towel cloth & & \\
\hline Gloves (sterile) sizes 6 to 8 & & & Absorbent cotton wool & & \\
\hline Gloves (examination) small, medium, large & & & $\begin{array}{l}\text { Urinary catheter Foleys disposable } \\
\# 12,14,18 \text { with bag }\end{array}$ & & \\
\hline Needle holder & & & Sheeting, plastic PVC clear & & \\
\hline Sterilizer & & & Waste disposal container & & \\
\hline Nail brush, scrubbing surgeon's & & & Face masks & & \\
\hline Vaginal speculum & & & Eye protection & & \\
\hline Bucket, plastic & & & Apron, utility plastic reusable & & \\
\hline Drum for compresses with lateral clips & & & Soap & & \\
\hline Examination table & & & Wash basin & & \\
\hline $\begin{array}{l}\text { Inventory list of equipment/supplies for } \\
\text { resuscitation }\end{array}$ & & & $\begin{array}{l}\text { Best practice guidelines available } \\
\text { at point of care }\end{array}$ & & \\
\hline $\begin{array}{l}\text { Supplementary equipment for use by } \\
\text { skilled health professionals }\end{array}$ & & & $\begin{array}{l}\text { Supplementary equipment for use } \\
\text { by skilled health professionals }\end{array}$ & & \\
\hline Magills Forceps (paediatric) & & & Laryngoscope handle & & \\
\hline Magills Forceps (adult) & & & $\begin{array}{l}\text { Laryngoscope Macintosh blades } \\
\quad \text { (adult) }\end{array}$ & & \\
\hline Endotrachael tubes uncuffed sizes 3.0 to 5.0 & & & $\begin{array}{l}\text { Laryngoscope Macintosh blades } \\
\text { (paediatric) }\end{array}$ & & \\
\hline Endotrachael tubes cuffed sizes 5.5 to 9 & & & $\begin{array}{l}\text { Spare bulbs, batteries for } \\
\text { laryngoscope }\end{array}$ & & \\
\hline IV Infusor bags & & & Stylet for Intubation & & \\
\hline Chest tubes insertion equipment & & & Cricothyroidotomy set & & \\
\hline
\end{tabular}

circumstances where this is not affordable or possible, such as by building on the existing, albeit informal, system of prehospital care and transport. This can include better organizing, training, and equipping first responders, such as police, fire service, and members of the lay public.
In terms of care at fixed facilities, including clinics and hospitals, WHO has worked collaboratively for several years with the International Society of Surgery on the Essential Trauma Care Project. This project has sought to set reasonable, affordable, minimum standards for trauma care 
services worldwide and to define the resources necessary to actually provide these services even in the lowest-income countries. A basic theme of the project is that considerable improvements in trauma care and its outcome can be achieved through improved organization and planning at a minimal increase in cost. Finally, this project seeks to actually catalyze such improvements in countries worldwide.

A milestone of the project has been the release several years ago of the publication Guidelines for Essential Trauma Care [10]. This publication lays out 11 core essential trauma care services which WHO and the International Society of Surgery feel that every injured person in the world could realistically be able to receive (Table 4). These include services that would be considered so straightforward that one may wonder why we should bother to state them so explicitly. The reason is that a great many trauma patients worldwide and, possibly, tragically, the majority, do not receive these services currently and we feel that they can and should.

In order to assure the availability of these services, the Guidelines delineates 260 individual items of human resources (skills, staffing and training) and physical resources (equipment and supplies) that should be considered either essential or desirable at the range of health facilities globally, ranging from rural clinics to tertiary care facilities (Table 5). Items that are essential (E) are those that are the most cost-effective and could realistically be provided to all injured persons treated at that level of the health care system anywhere in the world, even in the lowest income countries. Items that are desirable (D) are those that increase the likelihood of successful outcome, but are not as universally affordable as essential items. They are more applicable to middle-income countries or to very busy trauma care facilities in any location. These resource tables are intended to be a flexible matrix to be adjusted by planners in ministries of health or administrators and clinicians in individual hospitals to meet the local needs of the country or facility.
A key point to be emphasized is that the essential items should not just be physically present. Essential resources and services should actually be provided to all who need them in a timely fashion, without regard of ability to pay. Having a piece of equipment cannot be said to have met essential status if the equipment is nonfunctional for long periods of time while awaiting repairs, nor if it is unused due to insufficient staffing during periods of time (e.g. nights and weekends) when most injured patients need it. Having medications or other supplies in stock cannot be said to have met essential status if their use depends on payment in advance, a stipulation which many of the injured cannot meet. These stipulations do not rule out the need for billing or cost-recovery later, after essential items of care have been rendered. However, cost-recovery should not prevent rendering such essential care.

The Guidelines for EsTC cover the breadth of trauma care, including initial resuscitation, acute definitive care of injuries to specific body regions, and long-term rehabilitation. In general terms some of the types of services that the Guidelines seeks to promote, include, for the circumstances of low-income countries, such as in Africa and South Asia:

- Primary health care clinics (basic level) should have capabilities for rapid basic first aid, which many currently do not have. Though usually having only very basic capabilities, many of these facilities do receive a considerable number of injured persons, either due to the clinics' locations on major roadways or due to their geographical isolation and thus lack of any other health facilities in their vicinity.

- General practitioner (GP) staffed hospitals should have capabilities for chest tube insertion, airway maintenance and certain minimum blood transfusion capabilities, which many do not have.

- Specialists and tertiary care facilities should have capabilities for advanced airway management, including emergency endotracheal intubation, which many do

Table 4. Essential trauma care services [10]

- Obstructed airways are opened and maintained before hypoxia leads to death or permanent disability.

- Impaired breathing is supported until the injured person is able to breathe adequately without assistance.

- Pneumothorax and haemothorax are promptly recognized and relieved.

- Bleeding (external or internal) is promptly stopped.

- Shock is recognized and treated with intravenous (IV) fluid replacement before irreversible consequences occur.

- The consequences of traumatic brain injury are lessened by timely decompression of space occupying lesions and by prevention of secondary brain injury.

- Intestinal and other abdominal injuries are promptly recognized and repaired.

- Potentially disabling extremity injuries are corrected.

- Potentially unstable spinal cord injuries are recognized and managed appropriately, including early immobilization.

- The consequences to the individual of injuries that result in physical impairment are minimized by appropriate rehabilitative services.

- Medications for the above services and for the minimization of pain are readily available when needed. 
Table 5. Airway management: one of the 14 resource matrices in Guidelines for Essential Trauma Care [10]

\begin{tabular}{|c|c|c|c|c|}
\hline & \multicolumn{4}{|c|}{ Facility level* } \\
\hline & Basic & GP & Specialist & Tertiary \\
\hline \multicolumn{5}{|l|}{ Airway: knowledge \& skills } \\
\hline Assessment of airway compromise & $\mathrm{E}^{\dagger}$ & $\mathrm{E}$ & $\mathrm{E}$ & $\mathrm{E}$ \\
\hline Manual manoeuvres (chin lift, jaw thrust, recovery position, etc.) & $\mathrm{E}$ & $\mathrm{E}$ & $\mathrm{E}$ & $\mathrm{E}$ \\
\hline Insertion of oral or nasal airway & $\mathrm{D}$ & $\mathrm{E}$ & $\mathrm{E}$ & $\mathrm{E}$ \\
\hline Use of suction & $\mathrm{D}$ & $\mathrm{E}$ & $\mathrm{E}$ & $\mathrm{E}$ \\
\hline Assisted ventilation using bag-valve-mask & $\mathrm{D}$ & $\mathrm{E}$ & $\mathrm{E}$ & $\mathrm{E}$ \\
\hline Endotracheal intubation & $\mathrm{D}$ & $\mathrm{D}$ & $\mathrm{E}$ & $\mathrm{E}$ \\
\hline Cricothyroidotomy (with or without tracheostomy) & $\mathrm{D}$ & $\mathrm{D}$ & $\mathrm{E}$ & $\mathrm{E}$ \\
\hline \multicolumn{5}{|l|}{ Airway: equipment \& supplies } \\
\hline Oral or nasal airway & $\mathrm{D}$ & $\mathrm{E}$ & $\mathrm{E}$ & $\mathrm{E}$ \\
\hline Suction device: at least manual (bulb) or foot pump & $\mathrm{D}$ & $\mathrm{E}$ & $\mathrm{E}$ & $\mathrm{E}$ \\
\hline Suction device: powered: electric/pneumatic & $\mathrm{D}$ & $\mathrm{D}$ & $\mathrm{D}$ & $\mathrm{D}$ \\
\hline Suction tubing & $\mathrm{D}$ & $\mathrm{E}$ & $\mathrm{E}$ & $\mathrm{E}$ \\
\hline Yankauer or other stiff suction tip & $\mathrm{D}$ & $\mathrm{E}$ & $\mathrm{E}$ & $\mathrm{E}$ \\
\hline Laryngoscope & $\mathrm{D}$ & $\mathrm{D}$ & $\mathrm{E}$ & $\mathrm{E}$ \\
\hline Endotracheal tube & $\mathrm{D}$ & $\mathrm{D}$ & $\mathrm{E}$ & $\mathrm{E}$ \\
\hline Oesophageal detector device & $\mathrm{D}$ & $\mathrm{D}$ & $\mathrm{E}$ & $\mathrm{E}$ \\
\hline Bag-valve-mask & $\mathrm{D}$ & $\mathrm{D}$ & $\mathrm{E}$ & $\mathrm{E}$ \\
\hline Basic trauma pack & $\mathrm{D}$ & $\mathrm{E}$ & $\mathrm{E}$ & $\mathrm{E}$ \\
\hline Magill forceps & $\mathrm{D}$ & $\mathrm{D}$ & $\mathrm{E}$ & $\mathrm{E}$ \\
\hline Capnography & I & $\mathrm{D}$ & $\mathrm{D}$ & $\mathrm{D}$ \\
\hline Other advanced airway equipment & I & $\mathrm{D}$ & $\mathrm{D}$ & $\mathrm{D}$ \\
\hline
\end{tabular}

* Basic: outpatient clinics, often staffed by non-doctors; GP: hospitals staffed by general practitioners; Specialist: hospitals staffed by specialists, usually including a general surgeon; Tertiary: tertiary care hospitals, often university hospitals, with a wide range of specialists. ${ }^{\dagger}$ Items in the resource matrices are designated as follows: E: essential; D: desirable; I: irrelevant (not usually to be considered at the level in question, even with full resource availability).

Reproduced with permission from Guidelines for Essential Trauma Care [10].

not have. These large hospitals should also have quality improvement or medical audit programs in place, which few currently do.

Similar recommendations pertain to middle-income settings, such as Latin America, but desirable items figure more prominently.

The Guidelines is intended to be part planning guide for ministries of health or individual facilities and part advocacy document to be used by whoever wishes to push for improvements in trauma care. The legitimacy of this document for such advocacy is increased by the fact that it was created by the two bodies in the world that have the most credibility to do so, WHO and the International Society of Surgery, as well as by the fact the Guidelines was created with the review and other input of an additional thirteen organizations, including a variety of international subspecialty organizations (such as Orthopaedics Overseas and SICOT), as well as, several national organizations (such as the Academy of Traumatology of India).
The true value of the Guidelines lies in its actually catalyzing improvements of the care of the injured and examples of progress in several countries are given in Table 6.

As mentioned, several countries have undertaken needs assessments of trauma care capabilities using the criteria from the Guidelines as a template $[2,11,16,19,20]$. These needs assessments give some idea of priorities for ways in which care of musculoskeletal injuries could be strengthened (Table 7). In this survey of 100 institutions in 4 countries, resources for trauma care capabilities were assessed. These included human resources (staffing, skills, training), physical resources (equipment, supplies) and administrative mechanisms. The capabilities for care of musculoskeletal injuries are summarized (Table 7). In terms of human resources, large hospitals were fairly well supplied with fully trained orthopaedic surgeons, except in Africa, where general surgeons do most of the orthopaedic work. At small hospitals, only those in the middle country 
Table 6. Examples of progress in implementing the Guidelines for Essential Trauma Care in several individual countries [10]

\begin{tabular}{|c|c|}
\hline Ghana & $\begin{array}{l}\text { - Guidelines endorsed by Ghana Medical Association. } \\
\text { - Nationwide needs assessment conducted using Guidelines as basis [16]. } \\
\text { - High profile stakeholders conference held June, 2005. This adapted the Guidelines to Ghanaian circumstances and emphasized } \\
\text { implementation methods. It brought together trauma care professionals, Ministry of Health planners, WHO personnel, and several } \\
\text { members of Parliament. } \\
\text { - The meeting concluded with the development of a document: "Recommendations for a National Policy on Strengthening the Care } \\
\text { of Injured Persons in Ghana." }\end{array}$ \\
\hline India & $\begin{array}{l}\text { - India became one of the first "early innovators" to use the Guidelines. A stakeholders conference was conducted (2003) to adapt } \\
\text { Guidelines to Indian circumstances, where there are five, rather than four, levels and to discuss implementation strategies. These } \\
\text { are cosponsored by government and WHO. Stakeholders involved include trauma care clinicians from government and private } \\
\text { sector, non-government organizations, public health planners, and others. } \\
\text { - The above meeting also stimulated an expanded, nationwide meeting in } 2005 \text { entitled, "First National Consultation Meeting on } \\
\text { Trauma System Development in India," which expanded the essential trauma care concept to a nationwide scale and also } \\
\text { incorporated planning for prehospital services. } \\
\text { - Guidelines used as basis for needs assessments of trauma care capabilities in Gujarat state [11]. }\end{array}$ \\
\hline Mexico & $\begin{array}{l}\text { - Guidelines endorsed by Mexican Association for the Medicine and Surgery of Trauma (AMMCT). } \\
\text { - Nationally representative needs assessment conducted using Guidelines as basis under aegis of AMMCT and WHO county office } \\
\text { [2, 11]. } \\
\text { - Stakeholders conference conducted (2004) to adapt Guidelines to Mexican circumstances. This was sponsored by national Ministry } \\
\text { of Health and WHO. Stakeholders included presidents or representatives of most national professional societies that deal with } \\
\text { trauma and critical care, as well as ministry of health planners. } \\
\text { - The Guidelines has been translated into Spanish and re-published for use in Latin America. }\end{array}$ \\
\hline Vietnam & $\begin{array}{l}\text { - Guidelines used as basis for needs assessments of trauma care capabilities in several provinces. } \\
\text { - Findings of these needs assessments prompted low-cost improvements in trauma care in Hanoi area [19], an excellent example of } \\
\text { how the Guidelines can be used to stimulate on-the-ground improvements in trauma care. } \\
\text { - Guidelines has been translated into Vietnamese as collaborative effort of WHO country office and Vietnamese Ministry of Health, } \\
\text { and re-published locally, as has the Prehospital Trauma Care Systems. }\end{array}$ \\
\hline
\end{tabular}

Mexico have partial coverage by orthopaedists. At other small hospitals, either general surgeons or general practitioners provide care for musculoskeletal injuries. Even coverage by general surgeons is partial. At clinics, mostly care is provided by GPs, and a substantial amount by nurses and other nondoctor providers.

With nonspecialists providing much of the orthopaedic and other trauma and surgical care, continuing education courses become an important opportunity to strengthen such care, especially at first level health care facilities. All four countries had such courses available, such as Advanced Trauma Life Support in Mexico, National Trauma Management Course in India, or other similar locally developed courses in the other countries. However, coverage by such courses was very much suboptimal. In rural clinics, no one had such training. In small hospitals, far less than $50 \%$ of front line trauma care providers (e.g. doctors working in the ED or surgeons taking trauma call) had such training. Even in large hospitals, in most countries, less than $50 \%$ of front line trauma care providers had such training. The situation for continuing education for nurses was even lower.

Although ratings for such acute and definitive care showed some need for improvement, the situation with rehabilitation was even more difficult. Ratings showed significant deficiencies in the availability of human resources for rehabilitation, whether fully trained physician specialists or other providers such as physical therapists (PT), were considered. PT coverage was especially limited in availability at small hospitals.

In terms of physical resources for care of extremity injuries, fundamental items of orthopaedic trauma care were fairly well supplied at big hospitals. Portable X-ray was limited. Capabilities at small hospitals were much more limited. Related to the previously noted shortages of human resources for rehabilitation, availability of prosthesis for amputees was extremely limited at all levels.

Regarding the deficiencies noted for physical resources, often the problems were not the presence or absence of the equipment, but periods of inoperation while waiting for repairs, lack of supplies (such as film), or requirements for payment in advance before receiving services, which limited the availability of diagnostic tests to all who needed them. There were several instances in which mismatch of human and physical resources decreased availability of some services. For example, in India, several small hospitals had functioning X-ray machines and trained staff. 
Table 7. Resources for management of musculoskeletal injuries at 100 facilities in four countries: G: Ghana; V: Vietnam; I: India; M: Mexico $[2,11,16,19,20]$

\begin{tabular}{|c|c|c|c|c|c|c|c|c|c|c|c|c|}
\hline \multirow[t]{2}{*}{ Type of resource } & \multicolumn{4}{|c|}{ Clinic } & \multicolumn{4}{|c|}{ Small hospital } & \multicolumn{4}{|c|}{ Large hospital } \\
\hline & G & $\mathrm{V}$ & I & M & $\mathrm{G}$ & $\mathrm{V}$ & I & M & $\mathrm{G}$ & V & I & M \\
\hline Number of facilities evaluated & 4 & 14 & 28 & 5 & 8 & 8 & 14 & 4 & 2 & 5 & 1 & 7 \\
\hline
\end{tabular}

Human resources: acute care

Nurse in emergency department

Doctor for emergency call*

General surgeon*

Orthopaedic surgeon ${ }^{*}$

Anesthetist/anesthesiologist*

CE course for doctors ${ }^{\dagger}$

CE course for nurses*

Human resources: rehabilitation

Specialized rehabilitative nursing

Physical therapy

Physical medicine and rehabilitation specialist

Physical resources: extremity injury

Skeletal traction

External fixation

Internal fixation

X-ray

Portable X-ray

Image intensification ${ }^{\S}$

Limb prosthetics

Physical resources: wound care

Skin grafting

Tetanus prophylaxis (toxoid and anti-serum)

\section{Administrative functions}

Trauma-related quality improvement program

Trauma cases integrated into broader quality improvement programs

Trauma registry with severity adjustment

\begin{tabular}{|c|c|c|c|c|c|c|c|c|c|c|}
\hline 2 & 3 & 2 & 3 & 2 & 3 & 2 & 2 & 2 & 3 & 3 \\
\hline 0 & 1 & 1 & 2 & 2 & 3 & 3 & 3 & 3 & 3 & 3 \\
\hline na & na & na & na & 1 & 2 & 1 & 2 & 2 & 3 & 3 \\
\hline na & na & na & na & 0 & 0 & 0 & 2 & 0 & 3 & 3 \\
\hline na & na & na & na & 2 & 3 & 1 & 3 & 3 & 3 & 3 \\
\hline na & 0 & 0 & 0 & 1 & 1 & 0 & 1 & 1 & 1 & 1 \\
\hline 0 & 0 & 0 & 0 & 0 & 1 & 0 & 1 & 0 & 1 & 0 \\
\hline na & na & na & na & na & na & na & na & 0 & 1 & 0 \\
\hline na & na & na & na & 1 & 1 & 0 & 1 & 1 & 3 & 1 \\
\hline na & na & na & na & na & na & na & na & 0 & 2 & 1 \\
\hline na & na & na & na & 1 & 1 & 0 & 1 & 2 & 3 & 3 \\
\hline na & na & na & na & 0 & 1 & 0 & 1 & 1 & 3 & 3 \\
\hline na & na & na & na & 0 & 2 & 0 & 1 & 1 & 3 & 3 \\
\hline na & na & na & na & 1 & 2 & 2 & 3 & 2 & 3 & 3 \\
\hline na & na & na & na & 1 & 0 & 0 & 1 & 2 & 1 & 2 \\
\hline na & na & na & na & 0 & 0 & 0 & 0 & 0 & 1 & 1 \\
\hline na & na & na & na & 0 & 0 & 0 & 0 & 0 & 0 & 0 \\
\hline na & na & na & na & 1 & 2 & 1 & 2 & 2 & 3 & 3 \\
\hline 1 & 2 & 2 & 2 & 3 & 3 & 3 & 3 & 3 & 3 & 3 \\
\hline na & na & na & na & na & na & na & na & 0 & 0 & 0 \\
\hline 0 & 1 & 0 & 0 & 0 & 2 & 0 & 1 & 1 & 2 & 1 \\
\hline na & na & na & na & na & na & na & na & 0 & 0 & 0 \\
\hline
\end{tabular}

Adequacy of resource based on Guidelines for Essential Trauma Care [10] assessed as: NA (not applicable for that level); 0 (absent); 1 (inadequate, available to less than $50 \%$ of those who need it); 2 (partly adequate, available to greater than $50 \%$, but not everyone who needs it); 3 (adequate, available to virtually everyone who needs it).

Facility descriptions: Clinic: usually outpatient facility, but, some with significant volumes of trauma, especially those located along busy roads in more remote rural areas; Small hospital: in Africa called district, in India called community health centre. Usually performing some type of surgery, but with more limited range of specialist. Usually with around 50 - 200 beds; Large hospital: provincial, regional, with at least one or more category of specialist, usually over 200 beds, not including tertiary care centers.

* Available 24 hours per day, 7 day per week in hospital or promptly available on call from home; ${ }^{\dagger}$ Continuing Education (CE) course on trauma care, such as Advanced Trauma Life Support, National Trauma Management Course, or local equivalent: ideal is that all doctors who provide first line trauma care in emergency department and all general surgeons who provide trauma care are credentialed in such an in-service training course; ${ }^{*}$ Continuing Education (CE) course on trauma care, such as Trauma Nursing Core Course or local equivalent: ideal is that all nurses who provide first line trauma care in emergency department are credentialed in such an in-service training course; ${ }^{\S}$ Equipment that is categorized as "desirable" rather than "essential" in the Guidelines for EsTC.

However, the facilities were greatly limited in the number of plates (films) which they received each month. Thus many persons needing $\mathrm{X}$-rays did not receive this service. In Ghana, one large hospital had an image intensifier (Carm). However, there were no staff trained to use it and the machine lay idle. Many such problems are prime targets for improvement through strengthened organization and planning [11].

In all settings, there was a dearth of administrative functions to assure quality trauma care, including trauma registries, trauma-related quality improvement (medical audit) programs. 
This study and the broader Essential Trauma Care Project have identified several specific ways in which trauma care could be improved in an affordable and sustainable fashion. Much is being done well by many dedicated people working hard to confront the resource restrictions in their own environments. There are several ways in which their efforts could be aided. Several important, low-cost resources could be better provided at clinics/small hospitals in middle-income countries and at most facilities in low-income countries. More generally, in all settings, training and organization of trauma care could be improved, including such items as regular in-service training. Every country should define a core set of essential equipment and supplies (including those needed for musculoskeletal injury) and then assure and monitor the availability of such resources to all who need them. This is what is recommended by the Guidelines for Essential Trauma Care, which offers the first internationally-applicable standard for countries to use to assess their trauma systems. In so doing, the Guidelines offers a way to promote realistic, minimum standards for trauma care, in a comprehensive fashion worldwide.

World Health Assembly (WHA) Resolution on Trauma and Emergency Care Services

In an effort to promote greater efforts to strengthen trauma care, the WHA last year (2007) passed a resolution on trauma and emergency care services: WHA 60.22: "Health systems: emergency care system." The WHA is the governing board of the WHO. It consists of Ministers of Health of all 193 Member States. Its resolutions direct WHO's activities and carry considerable influence on actions of individual countries, as well as non-government organizations and funders. Last year, it passed for the first time ever a resolution encouraging governments worldwide to increase their efforts at providing care for trauma and other emergency conditions. The resolution listed 10 actions that Member States could take to achieve this, including measures like: "Identifying a core set of trauma services and developing methods to assure and document that such services are provided to all who need them." The full text of the resolution is available in all six UN languages on the WHO website at: www.who.int/gb/ebwha/pdf_files/ WHA60/A60_R22.en.pdf.

The resolution adds political endorsement to what many CORR readers have been working on for years. Clinicians active with care of the injured or anyone who wishes to promote improvements in care of the injured in their area can make use of this resolution by taking some of the following steps:
1. Making sure your ministries of health are aware of this resolution. It has been adopted by all 193 WHO Member States. Hence, in theory, it has the support of governments everywhere. However, this support variably filters down to the level of those who are making decisions on resources available for trauma care services. Appropriately bringing this resolution to their attention and indicating that the country's government supported it can help to increase political commitment for strengthening trauma care services.

2. Making sure that your Ministry of Health and local WHO office are aware of the expertise that you and your organizations have towards implementing this resolution.

3. Disseminating information about this resolution in your newsletters, journals, websites.

4. Pointing out, especially to donors and funders, how your activities are in keeping with the recommendations of this resolution. Many donors do take notice of WHA resolutions $[8,13]$.

In conclusion, there is a large burden of disability and even death from musculoskeletal injuries globally. This burden and suffering are all that much more tragic because they are so preventable, both through primary injury prevention such as road safety and through improvements in trauma and essential surgical care. Most of such improvements can be made in a sustainable and affordable fashion, even in the world's poorest countries.

Those who have attended the ABJS/C.T. Brighton Workshop on Trauma in the Developing World and the readership of Clinical Orthopaedics and Related Research at large are making considerable progress in carrying out such real world improvements. The authors of this article hope that some of the information presented will assist their efforts. For example, some of the WHO publications mentioned [10, 18, 23, 24] might be of assistance, whether for training efforts, trauma system planning, or other such efforts to improve the overall surgical services, especially at primary health care facilities. Some clinicians might find it beneficial to link up with those in the GIEESC. Likewise, some of the data on the extent of the burden of musculoskeletal injuries and information on the WHA Resolution on trauma and emergency care services might be of use in advocacy to increase attention to this problem.

Finally, these health care issues cannot be considered separately from broader societal and economic issues. Although much can be improved through improved organization and planning, more extensive improvements are hampered by economic constraints. Most countries can spend only very small sums on health. Increasing health expenditures is limited by overall poverty and often by restrictions imposed by the World Bank and other 
international financial institutions as part of loan repayment policies (formerly called structural adjustment policies). Care of the injured would be strengthened by measures that would allow greater funding of the health sector, including many measures being debated currently, such as debt relief, relaxation of restrictions on health system financing, and promoting a more equitable world economic order, such as by requiring the World Trade Organization proceedings and rule making to be open and democratic [6]. In addition to our own technical work, clinicians as individuals and as societies of professionals need to address these bigger global economic issues.

\section{References}

1. Ali J, Adams R, Butler AK, Chang H, Howard M, Gonsalves D, Pitt-Miller P, Stedman M, Winn J, Williams JI. Trauma outcome improves following the advanced trauma life support program in a developing country. J Trauma. 1993;34:890-898.

2. Arreola-Risa C, Mock C, Vega F, Romero Hicks E, Guzman Solana F, Porras G, Montiel G, de Boer M. Evaluating trauma care capabilities in Mexico with the World Health Organization's Guidelines for Essential Trauma Care. Pan Am J Public Health. 2006;19:94-103.

3. Arreola-Risa C, Mock CN, Lojero L, Cruz O, Garcia C, Canavati F, Jurkovich GJ. Low cost improvements in prehospital trauma care in a Latin American city. J Trauma. 2000;48:119-124.

4. Bach O, Hope M, Chaheka C, Dzimbiri K. Disability can be avoided after open fractures in Africa-results from Malawi. Injury. 2004;35:846-851.

5. Chardbunchachai W, Suppachutikul A, Santikarn C. Development of Service System for Injury Patients by Utilizing Data from the Trauma Registry (ISBN: 974-294-569-1). Khon Kaen, Thailand: Office of Research and Textbook Project, Khon Kaen Hospital; 2002.

6. Fort M, Mercer M, Gish O. Sickness and Wealth. Cambridge, MA: South End Press; 2004.

7. Krug EG, Sharma GK, Lozano R. The global burden of injuries. Am J Public Health. 2000;90:523-526.

8. Mock C. WHO Update: WHA resolution on trauma and emergency care services. Inj Prev. 2007;13:285-286.

9. Mock C, Boland E, Acheampong F, Adjei S. Long-term injury related disability in Ghana. Disabil Rehabil. 2003;25:732-741.
10. Mock C, Lormand JD, Goosen J, Joshipura M, Peden M. Guidelines for Essential Trauma Care. Geneva, Switzerland: WHO; 2004.

11. Mock C, Nguyen S, Quansah R, Arreola-Risa C, Viradia R, Joshipura M. Evaluation of trauma care capabilities in four countries using the WHO-IATSIC Guidelines for Essential Trauma Care. World J Surg. 2006;30:946-956.

12. Mock C, Quansah R, Krishnan R, Arreola-Risa C, Rivara F. Strengthening the prevention and care of injuries worldwide. Lancet. 2004;363:2172-2179.

13. Mock C, Arafat R, Chadbunchachai W, Joshipura M, Goosen J. What World Health Assembly Resolution 60.22 means to those who care for the injured. World J Surg. 2008;32:1636-1642.

14. Mock CN, Jurkovich GJ, nii-Amon-Kotei D, Arreola-Risa C, Maier RV. Trauma mortality patterns in three nations at different economic levels: implications for global trauma system development. J Trauma. 1998;44:804-814.

15. Peden M, Scurfield R, Sleet D, Mohan D, Hyder A, Jarawan E, Mathers C. World Report on Road Traffic Injury Prevention. Geneva, Switzerland: World Health Organization; 2004.

16. Quansah R, Mock C, Abantanga F. Status of trauma care in Ghana. Ghana Med J. 2004;38:149-152.

17. Rivara F, Mock C. The 1,000,000 lives campaign. Inj Prev. 2005; 11:321-323.

18. Sasser S, Varghese M, Kellermann A, Lormand J. Prehospital Trauma Care Systems. Geneva, Switzerland: World Health Organization; 2005.

19. Son NT, Mock C. Improvements in trauma care capabilities in Vietnam through use of the WHO-IATSIC Guidelines for Essential Trauma Care. Int J Inj Contr Saf Promot. 2006;13:125127.

20. Son NT, Thu NH, Tu NT, Mock C. Assessment of the status of resources for essential trauma care in Hanoi and Khanh Hoa, Vietnam. Injury. 2007;38:1014-1022.

21. World Health Organization. The Burden of Musculoskeletal Conditions at the Start of the New Millennium, Report of a WHO Scientific Group, WHO Technical Report Series 919. Geneva, Switzerland: WHO; 2003.

22. World Health Organization. Global burden of disease project 2002. Available at: http://www.who.int/healthinfo/bodproject/en/ index.html. Accessed July 28, 2008.

23. World Health Organization. Integrated management of emergency and essential surgical care (IMEESC) tool kit. Available at: http://www.who.int/surgery/publications/imeesc/en/index.html. Accessed December 3, 2007.

24. World Health Organization. Surgical Care at the District Hospital. Geneva, Switzerland: WHO; 2003. 